\title{
Multidecadal Modulation of ENSO Teleconnection with Europe in Late Winter: Analysis of CMIP5 Models ${ }^{\mathscr{O}}$
}

\author{
Jorge López PARAges, Belén Rodríguez de FonseCA, ${ }^{\mathrm{a}}$ Elsa MoHino, ${ }^{\mathrm{b}}$ \\ AND TERESA LOSADA ${ }^{\mathrm{a}}$ \\ Departamento de Física de la Tierra, Astronomía y Astrofísica I (Geofísica y Meteorología), Instituto de \\ Geociencias, Universidad Complutense de Madrid-Centro Mixto del Consejo Superior de \\ Investigaciones Científicas, Madrid, Spain
}

(Manuscript received 24 August 2015, in final form 11 July 2016)

\begin{abstract}
Many studies point to a robust ENSO signature on the North Atlantic-European (NAE) sector associated with a downstream effect of Rossby wave trains. Some of these works also address a nonstationary behavior of the aforementioned link, but only few have explored the possible modulating factors. In this study the internal causes within the ocean-atmosphere coupled system influencing the tropospheric ENSO-Euro-Mediterranean rainfall teleconnection have been analyzed. To this aim, unforced long-term preindustrial control simulations from 18 different CMIP5 models have been used. A nonstationary impact of ENSO on Euro-Mediterranean rainfall, being spatially consistent with the observational one, is found. This variable feature is explained by a changing ENSO-related Rossby wave propagation from the tropical Pacific to the NAE sector, which, in turn, is modulated by multidecadal variability of the climatological jet streams associated with the underlying sea surface temperature (SST). The results, therefore, indicate a modulation of the ENSO-Euro-Mediterranean rainfall teleconnection by the internal (and multidecadal) variability of the ocean-atmosphere coupled system.
\end{abstract}

\section{Introduction}

The El Niño-Southern Oscillation (ENSO) response at extratropical latitudes has been extensively related to the perturbation of the Aleutian low through changes

Supplemental information related to this paper is available at the Journals Online website: http://dx.doi.org/10.1175/ JCLI-D-15-0596.s1.

\footnotetext{
${ }^{\text {a }}$ Current affiliation: Departamento de Física de la Tierra, Astronomía y Astrofísica I (Geofísica y Meteorología), Instituto de Geociencias UCM-CSIC, Facultad de C.C. Físicas, Universidad Complutense de Madrid, Madrid, Spain.

${ }^{\mathrm{b}}$ Current affiliation: Departamento de Física de la Tierra, Astronomía y Astrofísica I (Geofísica y Meteorología), Facultad de C.C. Físicas, Universidad Complutense de Madrid, Madrid, Spain.

Corresponding author address: Jorge López Parages, Departamento de Física de la Tierra, Astronomía y Astrofísica I (Geofísica y Meteorología), Instituto de Geociencias UCM-CSIC, Facultad de C.C. Físicas, Universidad Complutense de Madrid (UCM), Pza de las Ciencias 1, 28040 Madrid, Spain.

E-mail: parages@fis.ucm.es
}

in the Pacific Hadley circulation in early winter and midwinter, and the poleward and eastward propagation of Rossby wave trains afterward (Honda et al. 2001; Moron and Gouirand 2003; Gouirand et al. 2007; Shaman and Tziperman 2011). Thus, ENSO can either produce a forced wavelike response across the North PacificAmerican sector, usually known as tropical Northern Hemisphere (TNH) pattern, or an alteration of internal atmospheric patterns, such as the so-called Pacific-North American (PNA) pattern [for more details, see Mo and Livezey (1986), Barnston and Livezey (1987), Livezey and Mo (1987), Trenberth et al. (1998), and Lee et al. (2008)]. In either case, it is not until January that the stationary wave anomalies generated by ENSO are completely established (Bladé et al. 2008).

The strongest ENSO signature on the North AtlanticEuropean (NAE) sector is usually found from January to April, after the peak of the ENSO event (NovemberFebruary; see, e.g., Brönnimann 2007). The resulting surface pattern resembles the North Atlantic Oscillation

Publisher's Note: This article was revised on 29 November 2016 to include an acknowledgment that was missing from the Acknowledgments section when originally published. 
(NAO) with a quasi-barotropic structure, and represents the leading rotational mode of upper-level streamfunction in the NAE region (García-Serrano et al. 2011). According to previous studies the ENSO-NAE teleconnection mechanism seems to be robust (e.g., Fraedrich and Müller 1992; Moron and Plaut 2003; Moron and Gouirand 2003), nonlinear (e.g., Wu and Hsieh 2004a,b; PozoVázquez et al. 2005), and seasonally varying (e.g., Mariotti et al. 2002; Moron and Gouirand 2003), the latter being especially noticeable in surface rainfall (Shaman 2014).

Recent literature has widely reported the existence of another global teleconnection pathway linking the ENSO phenomenon and European climate via the stratosphere (Ineson and Scaife 2009). This impact of ENSO on the Northern Hemisphere implies the upward propagation of planetary waves from the troposphere to the stratosphere in winter and the alteration of the stratospheric polar vortex (Manzini et al. 2006; Garfinkel and Hartmann 2008). The resulting anomalous perturbations are subsequently propagated downward to the troposphere in late winter (Ineson and Scaife 2009; Cagnazzo and Manzini 2009; Bell et al. 2009); this process is highly influenced by the frequency of occurrence of the so-called sudden stratospheric warmings (SSWs; Butler et al. 2014; Domeisen et al. 2015; Richter et al. 2015). At the surface, this teleconnection tends to be associated, like the tropospheric one, with an NAO-like pattern in late winter-spring, which makes difficult to distinguish between the troposphericrelated and the stratospheric-related signatures of ENSO over the North Atlantic, even more so when taking into account the large internal variability of the circulation at midlatitudes (Quadrelli and Wallace 2002).

Interestingly, the link between ENSO and the North Atlantic appears nonstationary in time (Knippertz et al. 2003; Sutton and Hodson 2003; Gouirand and Moron 2003; Greatbatch et al. 2004). In this context, although many papers indicate that ENSO's impact at surface levels over the NAE sector seems to be weak (e.g., García-Serrano et al. 2011), López-Parages and RodríguezFonseca (2012) have found a strong and significant impact of ENSO on European and Mediterranean (Euro-Mediterranean) rainfall in late winter but just for those decades throughout the twentieth century in coincidence with negative phases of the Atlantic multidecadal oscillation (AMO). This AMO-like evolution of the teleconnection is coherent with others observational studies (Mariotti et al. 2002; Knippertz et al. 2003). A nonstationary signature of ENSO in rainfall has also recently been detected in the nearby Arabian Peninsula (Kang et al. 2015). These results have contributed to the growing evidence advocating for a nonstationary behavior of the ENSO-NAE link on time scales ranging from decadal to multidecadal (RodríguezFonseca et al. 2016).

During the last years it has been demonstrated (see, e.g., Domeisen et al. 2015) that a good representation of the stratosphere could provide clear advances for the usually considered limited seasonal predictability of European climate (van Oldenborgh 2005). In the same sense, the aforementioned nonstationary teleconnections identified in previous studies suggest that the current predictability of ENSO impact over Europe through both the troposphere and the stratosphere could be variable and, at least for specific time periods, much greater than expected. Related to this, a recent sensitivity analysis carried out with an atmospheric general circulation model has demonstrated that the ENSO signature on Europe is sensitive to the ocean background conditions under which the ENSO phenomenon occurs (LópezParages et al. 2016). As the model used in this study does not include a well-resolved stratosphere, it can be inferred that the modulator has to be associated with changes in the troposphere. However, the underlying mechanisms explaining the possible role of the AMO, or maybe other multidecadal SST variability modes, in modulating the ENSO teleconnection with Europe via the troposphere are still unresolved.

It is necessary to note that the search for observational evidences of this possible multidecadal modulation presents serious difficulties. First, El Niño (and La Niña) forcing has varied in intensity (Torrence and Webster 1998; Sutton and Hodson 2003; Greatbatch et al. 2004) and spatial structure (An et al. 2006) in the past. Hence, to associate a changing remote impact of ENSO with an effective modulation in the propagation of the response toward distant regions, rather than with a direct effect of the nonstationary forcing itself, is highly complicated. Second, the observations are limited and present inhomogeneities in both space and time, which can introduce spurious nonstationary features. Related to this, van Oldenborgh and Burgers (2005) found little evidence for a changing behavior of ENSO teleconnections with global precipitation during the instrumental period, with the possible exception of Europe. Nevertheless, even though the uncertainties associated with observational data could be considered acceptable, the short data record raises questions about the confidence that one can have in results pointing to an atmospheric teleconnection changing at multidecadal time scales. As a consequence, long-term simulations from coupled global circulation models (CGCMs) emerge as a very convenient tool for testing responses associated with internal variability of the ocean-atmosphere coupled system. In this way, López-Parages et al. (2015) analyze, in a preindustrial control simulation of the CNRM-CM5 

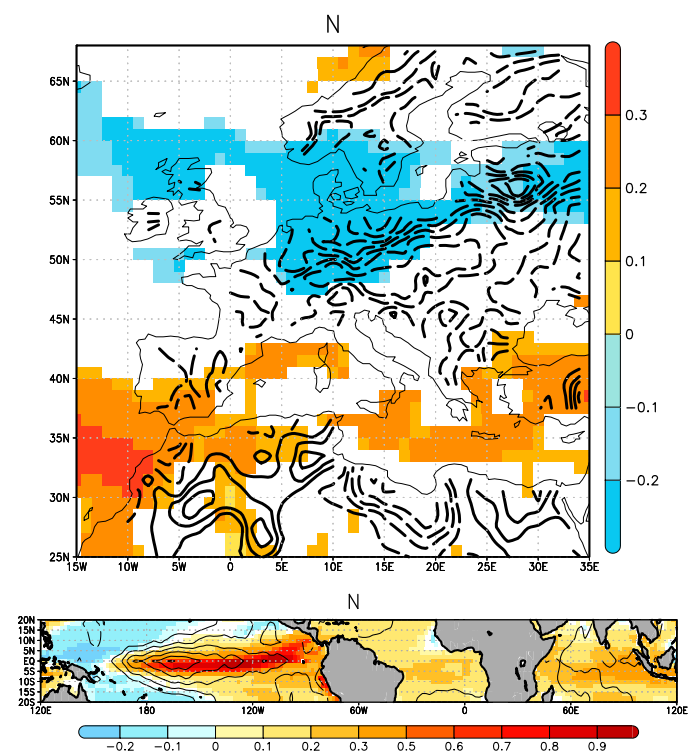

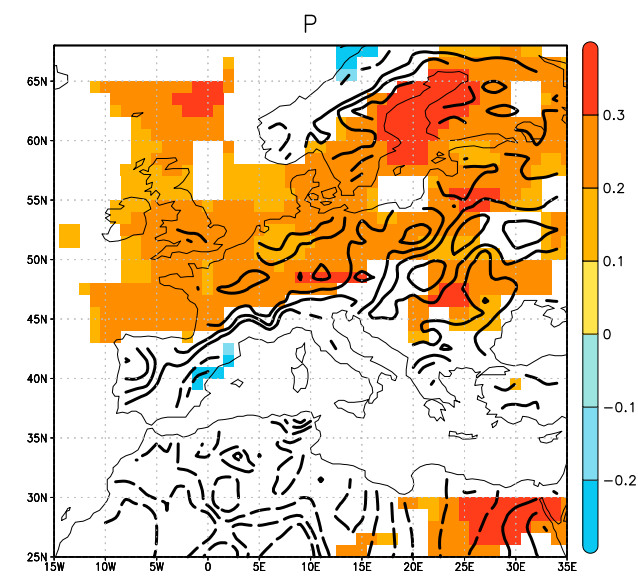

$P$

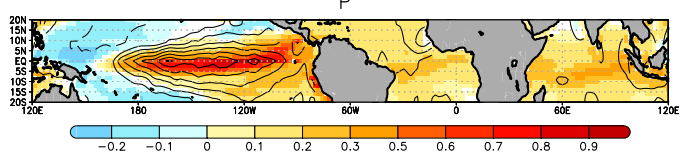

FIG. 1. (top) Heterogeneous and (bottom) homogeneous regression maps from a maximum covariance analysis carried out in (left) $\mathrm{N}$ and (right) $\mathrm{P}$ periods for observations (contoured; solid lines indicate positive values and dashed lines negative ones) and the CNRM-CM5 model (shaded the significant areas according a 400-trial Monte Carlo test at the $95 \%$ level). The $\mathrm{P}(\mathrm{N})$ represents $95 \%$ significant positive (negative) correlations (also according to a 400-trial Monte Carlo test) between the Euro-Mediterranean rainfall PC and the Niño-3.4 index. Units are standardized rainfall per standard deviation in SST expansion coefficient in (top), and kelvin per standard deviation in SST expansion coefficient in (bottom). For both variables the minimum (maximum) contour represented, for positive (negative) values, is $0.1(-0.1)$, with the contour interval $(\mathrm{CI})=0.1$. Modified from López-Parages et al. (2015).

coupled model, the ENSO-Euro-Mediterranean rainfall link in late winter-early spring (averaged for the February-April season). Periods with positive and negative significant correlations between the Niño-3.4 index and the rainfall variability in central Europe are found, in accordance with the observed changing link detected throughout the twentieth century (Fig. 1). Hereinafter these periods with opposite relations between ENSO and the European rainfall will be referred to as $\mathrm{P}$ (positive correlations) and $\mathrm{N}$ (negative correlations), respectively. Taking into account that the CNRM-CM5 model used in López-Parages et al. (2015) does not include a well-resolved stratosphere, the authors propose that the main modulating driver in the ENSO-NAE teleconnection are the changes in the mean flow at the upper troposphere, which they associate with internal alterations in the ocean-atmosphere coupled system over the midlatitudes of the North Pacific Ocean (between $30^{\circ}$ and $60^{\circ} \mathrm{N}$, approximately). As noted above, ENSO influence in the NAE sector is mainly related to Rossby wave trains propagation in late winter. According to the linear barotropic theory, propagation of extratropical Rossby waves highly depends on the intensity and spatial configuration of the zonal mean flow and, hence, on the extratropical jet streams. As shown in Branstator (2002), in those regions where jets are weak the perturbations coming from the tropics propagated toward high latitudes, and afterward they are refracted at a certain location toward lower latitudes. They tend to describe, therefore, an arching pattern with a prominent meridional structure and much more limited zonal extent. On the contrary, in those regions where jet streams are intense the planetary waves are efficiently trapped in the zonal flow, describing a global hemispheric structure (Hoskins and Karoly 1981; Branstator 1983, 2002; Hoskins and Ambrizzi 1993; Ambrizzi et al. 1995). Considering that extratropical jets are partially driven by the meridional atmospheric temperature gradients, a change in the spatial configuration of the former is expected if the underlying surface temperature varies throughout the time. As a consequence, a change in tropical-extratropical teleconnections associated with Rossby waves (as the ENSONAE link in late winter) is also expected.

The purpose of the present work is to make a step forward in the study of the internal causes, within the ocean-atmosphere system, that could explain the multidecadal modulation of ENSO's impact on European rainfall. We focus on the SST-modulated tropospheric pathways of the ENSO-related Rossby wave trains that impact the NAE sector. To this end, long-term control simulations with preindustrial forcings from phase 5 of 
TABLE 1. Description of CMIP5 models. From left to right, number of model, name of model, piControl simulation length, original horizontal resolution, atmospheric vertical layers, and references. (Expansions of acronyms are available online at http://www.ametsoc. org/PubsAcronymList.)

\begin{tabular}{rlcccl}
\hline \hline No. & \multicolumn{1}{c}{ Model name } & piControl length & Resolution (lon $\times$ lat) & Atm vertical layers & References \\
\hline 1 & BCC_CSM1.1 & 500 & $2.8^{\circ} \times 2.8^{\circ}$ & 26 & Xin et al. (2013) \\
2 & CanESM2 & 996 & $2.8^{\circ} \times 2.8^{\circ}$ & 40 & Chylek et al. (2011) \\
3 & CCSM4 & 501 & $1.3^{\circ} \times 0.9^{\circ}$ & 27 & Gent et al. (2011) \\
4 & CNRM-CM5 & 850 & $1.4^{\circ} \times 1.4^{\circ}$ & 31 & Voldoire et al. (2013) \\
5 & CSIROMk3.6.0 & 500 & $1.9^{\circ} \times 1.9^{\circ}$ & 18 & Rotstayn et al. (2010) \\
6 & GISS-E2-R & 550 & $2.5^{\circ} \times 2.0^{\circ}$ & 40 & Schmidt et al. (2014) \\
7 & GISS-E2-H & 540 & $2.5^{\circ} \times 2.0^{\circ}$ & 40 & Schmidt et al. (2014) \\
8 & FGOALS-g2 & 700 & $1.8^{\circ} \times 2.8^{\circ} \times 1.3^{\circ}$ & 26 & Bao et al. (2013) \\
9 & HadGEM2-CC & 240 & $1.9^{\circ} \times 1.3^{\circ}$ & 60 & Martin et al. (2011) \\
10 & HadGEM2-ES & 575 & $3.0^{\circ} \times 1.5^{\circ}$ & 21 & Martin et al. (2011) \\
11 & INM-CM4.0 & 500 & $2.4^{\circ} \times 1.4^{\circ}$ & Volodin et al. (2010) \\
12 & MIROC5 & 670 & $2.8^{\circ} \times 2.8^{\circ}$ & 80 & Watanabe et al. (2010) \\
13 & MIROC-ESM-CHEM & 255 & $1.9^{\circ} \times 1.9^{\circ}$ & 47 & Watanabe et al. (2011) \\
14 & MPI-ESM-LR & 1000 & $1.1^{\circ} \times 1.1^{\circ}$ & 48 & Giorgetta et al. (2013) \\
15 & MRI-CGCM3 & 500 & $2.5^{\circ} \times 1.9^{\circ}$ & Yukimoto (2011) \\
16 & NorESM1-M & 501 & $3.8^{\circ} \times 1.9^{\circ}$ & 26 & Bentsen et al. (2013) \\
17 & IPSL-CM5A-LR & 1000 & $0.6^{\circ} \times 0.6^{\circ}$ & 39 & Dufresne et al. (2013) \\
18 & MIROC4h & 100 & 56 & Sakamoto et al. (2012) \\
\hline
\end{tabular}

the Coupled Model Intercomparison Project (hereinafter piControl-CMIP5; Taylor et al.2012) have been used to better characterize the internal ENSO-NAE teleconnection. In particular, the study addresses the following questions: 1) Is the observed nonstationary impact of ENSO over European rainfall reproduced by piControl-CMIP5 simulations? 2) What is the internal underlying dynamical mechanism for the change of that impact? 3) Can it be explained by changes in the mean flow at upper troposphere (represented here at $200 \mathrm{hPa}$ ) associated with well-known SST multidecadal variability modes?

The paper is organized as follows. Section 2 describes the data and methods used in this study. Section 3 presents the different results obtained from distinct procedures and the relationship among them. Finally, section 4 gives a summary and discussion.

\section{Data and methods}

a. Data

As previously noted, the present study is focused on unforced long-term preindustrial control simulations (piControl). In particular, the outputs from 18 different CMIP5 models have been used (see Table 1). For all of them the following fields, subject to previous interpolation onto a common regular $2.8^{\circ} \times 2.8^{\circ}$ global grid, are analyzed: surface rainfall, sea surface temperature, and zonal mean flow at $200 \mathrm{hPa}$. Here, the streamfunction at the later level $(200 \mathrm{hPa})$ has been obtained by solving the Poisson equation, which connects streamfunction and vorticity [see Swarztrauber and Sweet (1975) for more details]. As mentioned in the introduction, this paper is focused on the nonstationary behavior of the tropospheric pathway linking ENSO and the European rainfall variability. Thus, we consider both models that resolve the stratosphere and its dynamics and models that do not.

\section{b. Methods}

\section{1) DATA FILTERING AND STATISTICAL ANALYSIS}

As in López-Parages et al. (2015), in order to focus the analysis on the nonstationary ENSO-NAE teleconnection at interannual time scales, a 7-yr high-pass filter based on a discrete Fourier transform is applied to all the fields. Some regression patterns shown throughout this study are constrained to the statistically significant response. In these cases the significance has been always determined according to the nonparametric "random phase" test (Ebisuzaki 1997). This test is specifically designed to estimate the statistical correlation of time series that show serial correlation, and it is based on resampling the phase in the frequency domain, preserving the power spectrum.

\section{2) INDEPENDENT EOFs}

To determine the directions in which the maximum variability of the anomalous rainfall is organized in the models, empirical orthogonal functions (EOFs) of the late winter-early spring (February-April) EuroMediterranean precipitation is computed for each 
piControl simulation. According to previous studies [see, e.g., Fig. 1 from López-Parages et al. (2015)], the leading principal component (PC) of observed European interannual rainfall in the aforementioned season projects onto a spatial pattern with three centers of action over Scandinavia, central Europe, and the Mediterranean region. This PC is related to the Niño-3.4 index in particular decades, a feature that can be checked by correlating both time series in a sliding window spanning 20 years, that is, by moving a 20-yr-long window, year per year, throughout the whole time series.

In the present study the same procedure is applied to calculate independent EOFs, for each model, as follows: 1) the PC that projects onto a spatial rainfall structure closer to the observed leading EOF (based on the pattern correlation) is selected for each model; 2) a 20-yr moving correlation is applied between this PC and the Niño-3.4 index, being the statistical significance of each local correlation assessed by a 400-trial Monte Carlo test (where both the PC and the Niño-3.4 index are used in a random permutation of 400 times); 3) those years within a $95 \%$ significant correlation period (in which the real correlation has a magnitude greater than the $95 \%$ of the randomly generated correlations) are selected; and 4) the pieces of the PC related to these selected years are assembled and projected on a particular field of interest. The aforementioned methodology has been applied in order to maintain, as much as possible, consistency with López-Parages and Rodríguez-Fonseca (2012) and López-Parages et al. (2015). Once the entire procedure is implemented for each model the resulting regression maps are analyzed together as a whole by computing the ensemble mean. It is worth mentioning that a simple linear regression of the rainfall field onto the Niño-3.4 index could give a more accurate idea of the rainfall response to ENSO. However, following this methodology we could be mixing the impact of ENSO on distinct rainfall modes, which would strongly complicate the comparison of our results with those from López-Parages and Rodríguez-Fonseca (2012) and López-Parages et al. (2015). Another possibility would be to project the CMIP5 seasonal anomalies on the observed leading mode of rainfall. However, such an approach would tightly constrain the simulations to follow observations, while we particularly wanted to analyze the rainfall variability simulated by the models, to know if the leading EOF identified in CMIP5 models corresponds to the leading observational EOF, and also to analyze the relative importance of this variability mode in each model. For all the aforementioned reasons the present paper has been based on rainfall EOFs by the application of the already described independent EOFs.

\section{3) El NiÑO-RAINFALL EOF}

A new approach has been proposed in this study in order to characterize the most frequent ways in which El Niño can influence European rainfall. The method is also based on EOF analysis but, in this case, the EOF is applied to a matrix $\mathbf{M}$ that compiles a group of correlation maps calculated between the rainfall and the Niño3.4 index in a 20-yr sliding window. All models and all 20-yr correlation maps are included in $\mathbf{M}$, for which the covariance matrix $\mathbf{C}$ has been maximized. Hence, the correlation matrix $\mathbf{M}$ with elements of each year $i$ and spatial point $j$, and its related covariance matrix $\mathbf{C}$, are given by

$$
\begin{aligned}
M_{i, j} & =\operatorname{corr}[R(i: i+19, j), \mathrm{N} 34(i: i+19)], \\
i & =1, \ldots, N-20, \quad j=1, \ldots, \mathrm{ns} \text { and } \\
\mathbf{C} & =\mathbf{M M}^{\mathrm{T}},
\end{aligned}
$$

where $R$ and N34 represent the rainfall field and the Niño-3.4 index, respectively, and $\mathbf{M}^{\mathrm{T}}$ denotes the transposed matrix $\mathbf{M}$. This resulting matrix $\mathbf{M}$ has therefore the same spatial dimension (ns) as the input rainfall data but a temporal dimension $(N-20)$ reduced in 20 values in comparison with both, the rainfall field and the Niño3.4 index (with $N$ time values each, that is, the total amount of years considering the 18 models). This new method has two main advantages. On the one hand, as the EOF is based on the El Niño-rainfall correlation matrix $\mathbf{M}$, the resulting modes (if they are physically consistent) represent recurrent spatial patterns that relate El Niño and rainfall and not only a variability mode of rainfall (which might or might not be related to ENSO). The associated PCs can therefore be interpreted as the time evolution of these specific links, that is, the low-frequency variability of the El Niñorainfall link. On the other hand, as $\mathbf{M}$ is constructed by combination of all CMIP5 models, the resulting EOFs represent common variability patterns. This procedure based on the concatenation of multiple runs from distinct GCMs and its study through a discriminant analysis technique has been already applied in the past (Ward and Navarra 1997). With this methodology, the length of a data sample representing a specific dynamical mechanism, which is highly constrained in observational studies, is maximized. As will be demonstrated throughout this study, the use of this method makes possible a better interpretation of the results obtained from the independent EOFs of the anomalous rainfall only, and provides a better understanding of the reliability of coupled models in capturing teleconnections. To this aim, the significant correlations obtained from the independent EOFs will be separated into two 
TABLE 2. From left to right, name of model, $\mathrm{PC}$ associated with that Euro-Mediterranean rainfall EOF that is spatially closest to the leading observational EOF, spatial correlation between the selected EOF and the leading observational EOF (corr EOF $1_{\mathrm{obs}}$ ), and variance explained by the corresponding mode (exp var).

\begin{tabular}{lccc}
\hline \hline \multicolumn{1}{c}{ Model name } & PC & Corr EOF1 $_{\text {obs }}$ & Exp var \\
\hline BCC_CSM1.1 & PC2 & 0.86 & 17.3 \\
CanESM2 & PC2 & 0.92 & 11.5 \\
CCSM4 & PC2 & 0.92 & 13.2 \\
CNRM-CM5 & PC1 & 0.92 & 14.6 \\
CSIRO Mk3.6.0 & PC2 & 0.84 & 10.8 \\
GISS-E2-R & PC1 & 0.93 & 19.1 \\
GISS-E2-H & PC1 & 0.94 & 17.5 \\
FGOALS-g2 & PC2 & 0.58 & 10.9 \\
HadGEM2-CC & PC2 & 0.84 & 14.4 \\
HadGEM2-ES & PC2 & 0.85 & 16.1 \\
INM-CM4.0 & PC2 & 0.95 & 16.8 \\
MIROC5 & PC2 & 0.92 & 13.1 \\
MIROC-ESM-CHEM & PC2 & 0.90 & 14.4 \\
MPI-ESM-LR & PC2 & 0.92 & 15.3 \\
MRI-CGCM3 & PC2 & 0.88 & 13.2 \\
NorESM1-M & PC2 & 0.92 & 13.5 \\
IPSL-CM5A-LR & PC2 & 0.84 & 15.8 \\
MIROC4h & PC2 & 0.72 & 13.4 \\
\hline
\end{tabular}

different clusters and represented in a mathematical base defined from this new El Niño-rainfall EOF. Furthermore, the centroids associated with each cluster, which are based on pairwise Euclidean distances between points, are calculated by a $k$-means clustering method (Lloyd 1982).

\section{Results}

\section{a. Euro-Mediterranean rainfall modes in CMIP5 models}

The leading EOF of interannual rainfall obtained in observations, whose corresponding PC is significantly correlated with ENSO during some decades in the twentieth century [see Fig. 1 from López-Parages et al. (2015)], appears, in most of the CMIP5 models, as the second EOF (Table 2). These rainfall variability modes explain, on average, around a $15 \%$ of the total variance, CSIRO Mk3.6.0 and GISS-E2-R being the extreme cases with $10.8 \%$ and $19.1 \%$, respectively. Except for INM-CM4.0 all the mentioned modes are considered robust according to the criteria of North et al. (1982). Following this criterion a certain mode can be considered as an independent mode (not a random mixture of true modes) if the spacing with its neighboring modes is clearly larger than the sampling error of the corresponding mode. There is no overlap of the mode of interest sampling error with that of the closest neighbor in any of the models analyzed. The only exception is
INM-CM4.0, for which a very slight overlap is found. Thus, the independence of the variability modes studied here is reinforced, which facilitates their physical interpretations.

Two independent samples are then constructed by selecting, for each model, those periods in which the PCs associated with the aforementioned rainfall modes are significantly positive or negative correlated with the Niño-3.4 index, defining therefore the so-called $\mathrm{P}$ and $\mathrm{N}$ samples. As was indicated in the previous section, the ensemble mean of regression maps calculated by the projection of these selected fragments of the PCs onto the Euro-Mediterranean rainfall and the global SST in both $\mathrm{P}$ and $\mathrm{N}$ is obtained (Figs. 2a-d). In agreement with the observations (contoured in Fig. 1), in P periods, El Niño (La Niña) is related to positive (negative) rainfall anomalies over central Europe, the British Isles, and the northwestern part of the Iberian Peninsula, together with negative (positive) anomalies in the Mediterranean region and northern Scandinavia. In N, on the contrary, the sign obtained at the aforementioned regions is broadly the opposite. The ensemble mean of the rotational flow in terms of the regression maps of the streamfunction at $200 \mathrm{hPa}$ has been also plotted for $\mathrm{P}$ and $\mathrm{N}$ samples (shaded in Figs. 2e,f), finding a noticeably reduced impact over the extratropical Northern Hemisphere in the latter case. These differences identified, for CMIP5 models, in the rotational response of ENSO in P and $\mathrm{N}$ periods are highly consistent with those found in the observational record (contoured in Figs. 2e,f). The similarities between the simulated (shaded in Fig. 2f) and the observed (contoured in Fig. 2f) wave responses are specially striking in $\mathrm{P}$ periods. In particular, this rotational response in $\mathrm{P}$ reflects a clear $\mathrm{TNH}$ pattern over the North Pacific-American sector together with a negative center over northern Europe, resembling the documented leading rotational mode of upper-level streamfunction in the NAE sector (García-Serrano et al. 2011). The coherence in the sign of the anomalies among the different models (note the black marks in Fig. 2) reinforces the robustness of the above mentioned spatial patterns. A significant feature is that these noticeably different impacts of El Niño on the upper troposphere at extratropical latitudes and on the EuroMediterranean rainfall are related to almost the same SST El Niño spatial pattern (Figs. 2c,d). This changing signature of ENSO over the NAE sector obtained in piControl-CMIP5 simulations is consistent with the observations (contoured in Figs. 1, top, and 2e,f) and hence it reinforces the hypothesis of a nonstationary teleconnection associated with internal variability of the coupled ocean-atmosphere system. The main objective for the rest of this paper is to understand why a very 
a)

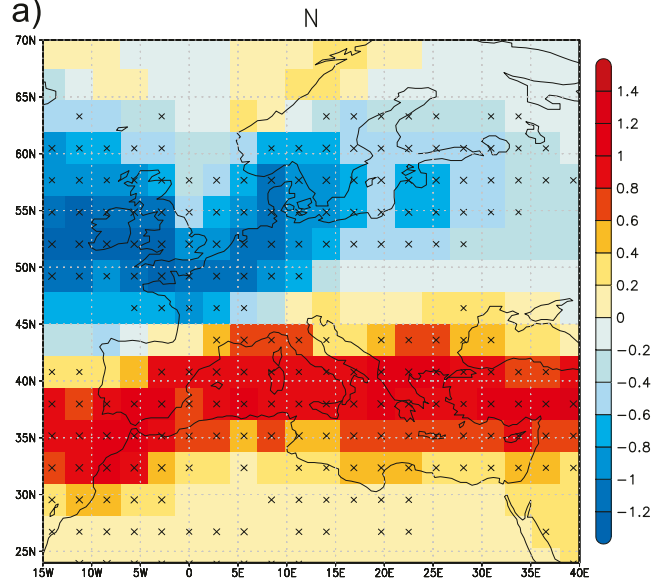

c)

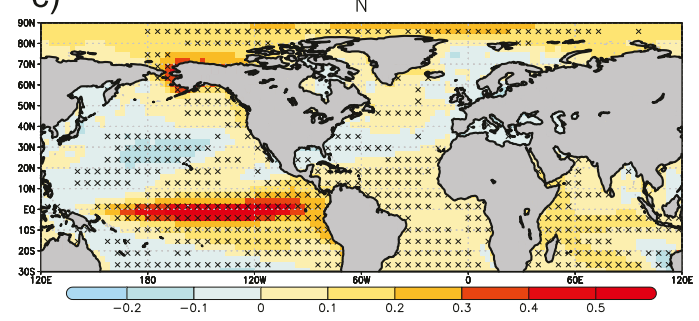

e)

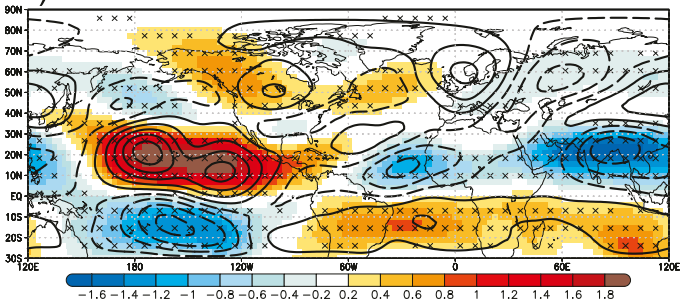

b)

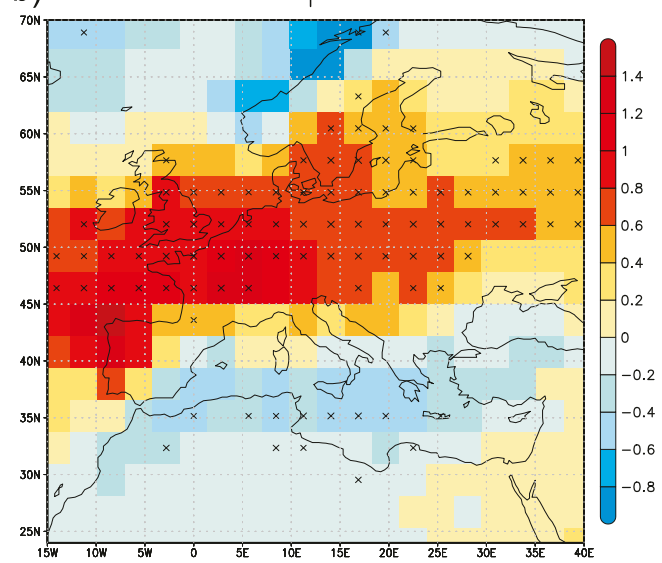

d)
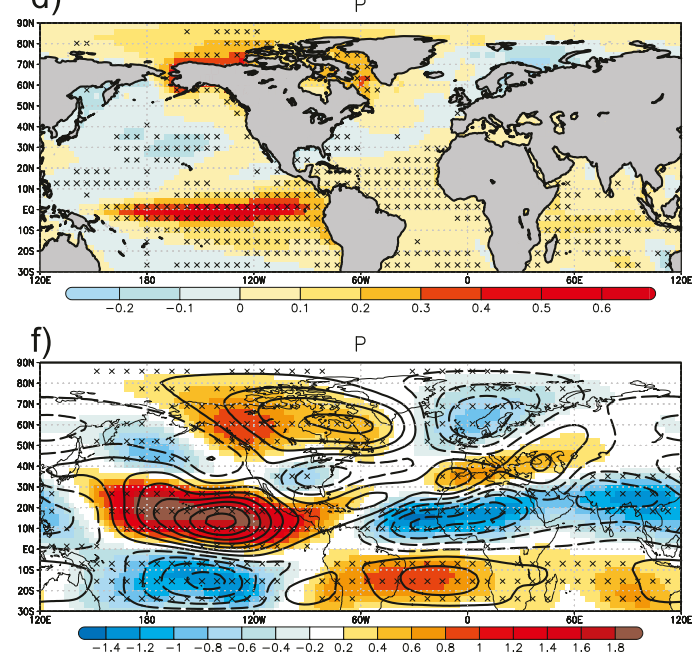

FIG. 2. Interannual patterns: shading indicates the regression of (a), (b) rainfall $\left(10^{6} \mathrm{~kg} \mathrm{~m}^{-2} \mathrm{~s}^{-1}\right)$, (c),(d) SST (K), and (e),(f) streamfunction at $200 \mathrm{hPa}\left(10^{5} \mathrm{~m} \mathrm{~s}^{-2}\right)$ onto the Euro-Mediterranean rainfall $\mathrm{PC}$ and averaged over the 18 CMIP5 models in those periods in which the correlation between the PC and the Niño-3.4 index is (left) negative or (right) positive at the $95 \%$ significance level (according to a 400-trial Monte Carlo test). In (e) and (f) the high minus low composite maps (solid lines indicate positive values and dashed lines negative) characterizing the changing ENSO-Euro-Mediterranean rainfall link throughout the twentieth century [taken from Fig. 5 of López-Parages et al. (2015)] have also been added. The PC is selected, for each CMIP5 model, as the PC related to the spatially closest EOF to the observational EOF associated with ENSO [Fig. 1 from López-Parages et al. (2015)]. The black marks indicate the points where the regression coefficient sign coincides in at least 14 of the 18 models analyzed.

similar El Niño pattern (Figs. 2c,d) could be related to such different rainfall responses in Europe (Figs. 2a,b), specifically addressing the role played by the lowfrequency changes in the internal climate system.

\section{b. ENSO-Euro-Mediterranean rainfall link in a new base}

As explained in section $2 \mathrm{~b}(2)$, Figs. 2a,b are constructed by averaging, for selected periods $(\mathrm{P}$ and $\mathrm{N})$, the EOFs from CMIP5 models that are the spatially closest to the leading observational Euro-Mediterranean rainfall EOF. However, although the selected modes can be similar among the different models, they are obtained by independent EOF analysis. Hence, as climate variability can be organized in different patterns for each model, these selected EOFs may represent distinct underlying dynamics. To shed further light on this issue, a new and common EOF for all CMIP5 models, which is based on a matrix that compiles a group of correlation maps calculated between rainfall and the Niño-3.4 index in a 20-yr moving window, is calculated [see section $2 b(2)$ for a more detailed description]. Hereinafter this new EOF will be referred to as the multidecadal Niño correlation EOF (mnc-EOF) in contrast to the ones previously described in subsection $3 a$. The resulting mnc-EOF patterns represent therefore how the variability of the link 
a)

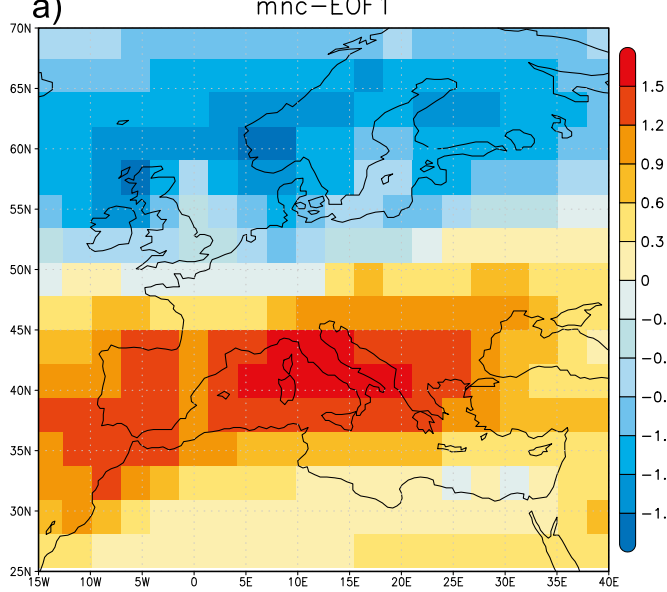

c)

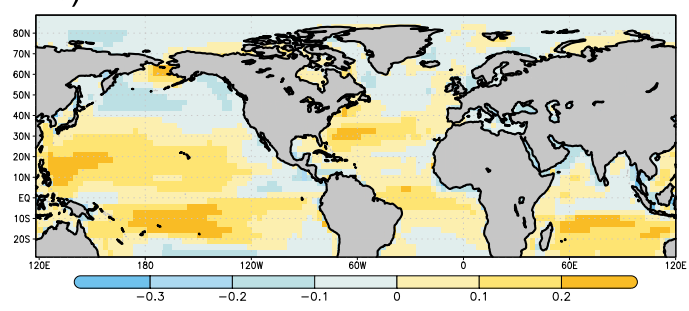

b) $\quad m n c-E O F 2$

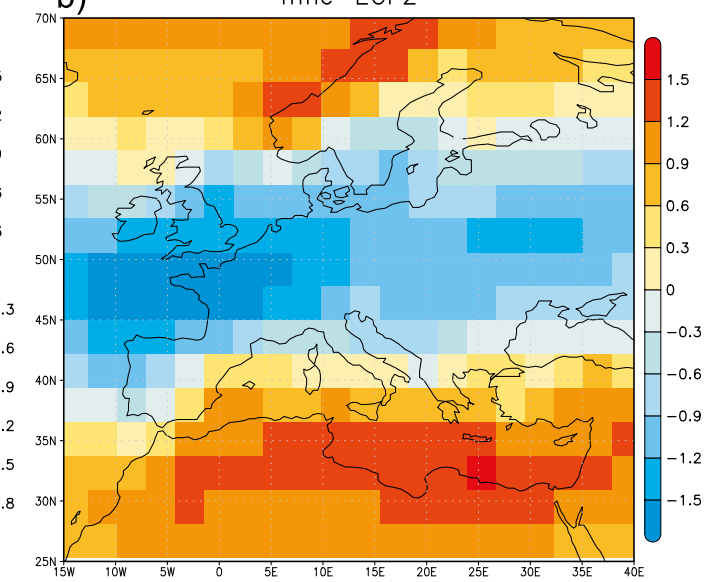

d)

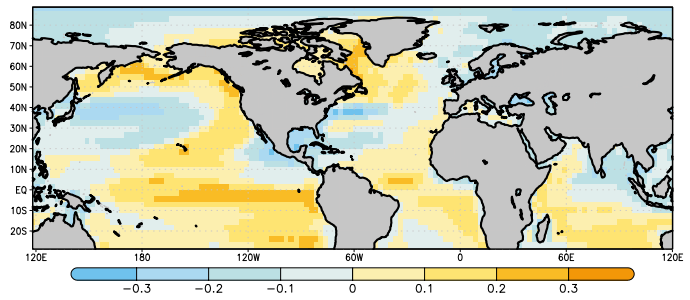

e)

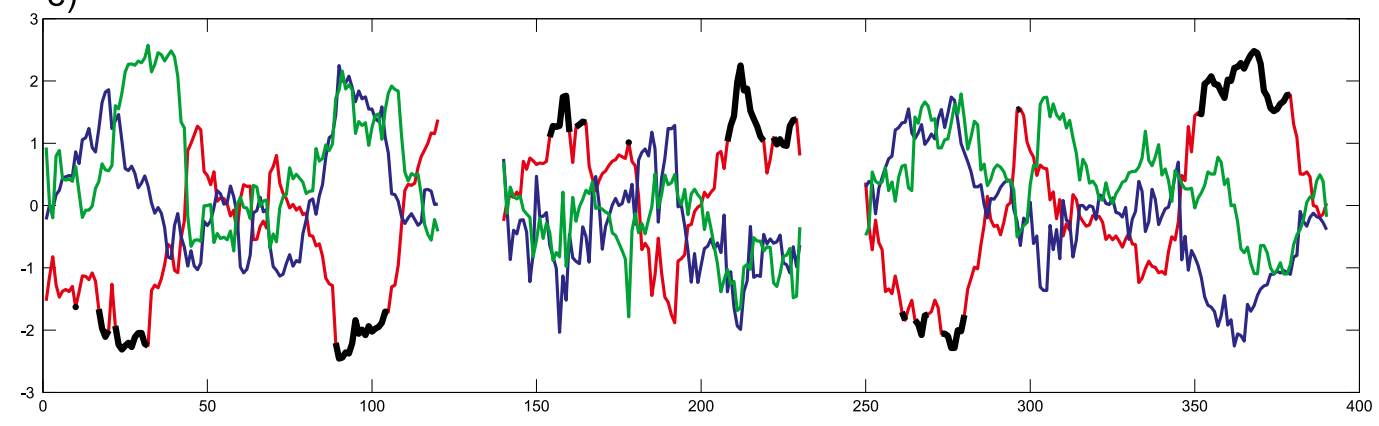

FIG. 3. New base from El Niño-rainfall EOF: (a) mnc-EOF1 (20.2\% variance explained) and (b) mnc-EOF2 (14.4\% variance explained) of the ensemble multidecadal correlation matrix between rainfall and ENSO (for each spatial point, the 20-yr sliding windows correlation between rainfall and the Niño-3.4 index is included). Units are 10 times the correlation per standard deviation in mnc-PC1 and mnc-PC2, respectively. Correlation maps between the SST and (c) mnc-PC1 and (d) mnc-PC2. (e) Some selected periods (specifically for CNRM-CM5, HadGEM2-ES, and MIROC-ESM-CHEM models) of mnc-PC1 (blue), mnc-PC2 (green), and the 20-yr sliding windows correlation between the interannual-PC (Euro-Mediterranean rainfall) and the Niño-3.4 index (red; in black those $95 \%$ significant correlations according to a 400-trial Monte Carlo test) are shown in order to illustrate the relationship among them.

between ENSO and the Euro-Mediterranean rainfall is organized in CMIP5 models, and the related multidecadal Niño correlation principal components (mnc-PCs) represent the evolution of these modes of variability of the teleconnection at multidecadal time scales. The first and second leading modes, which are well separated according the criteria developed by North et al. (1982), are shown in Fig. 3. The leading mnc-EOF is characterized by negative correlations over northern Europe and positive ones over the northern side of the Mediterranean region, while the second mncEOF is associated with positive correlations in northern Scandinavia and the southern part of the Mediterranean Sea, and negative correlations in the west side of central Europe (Figs. 3a,b). Note that the maximum (minimum) correlations identified in mnc-EOF1 and mnc-EOF2 are, approximately, $0.2(-0.2)$ per standard deviation in mnc$\mathrm{PC} 1$ and mnc-PC2. This represents, for instance, correlations around $0.4(-0.4)$ for principal component values around 2 . 


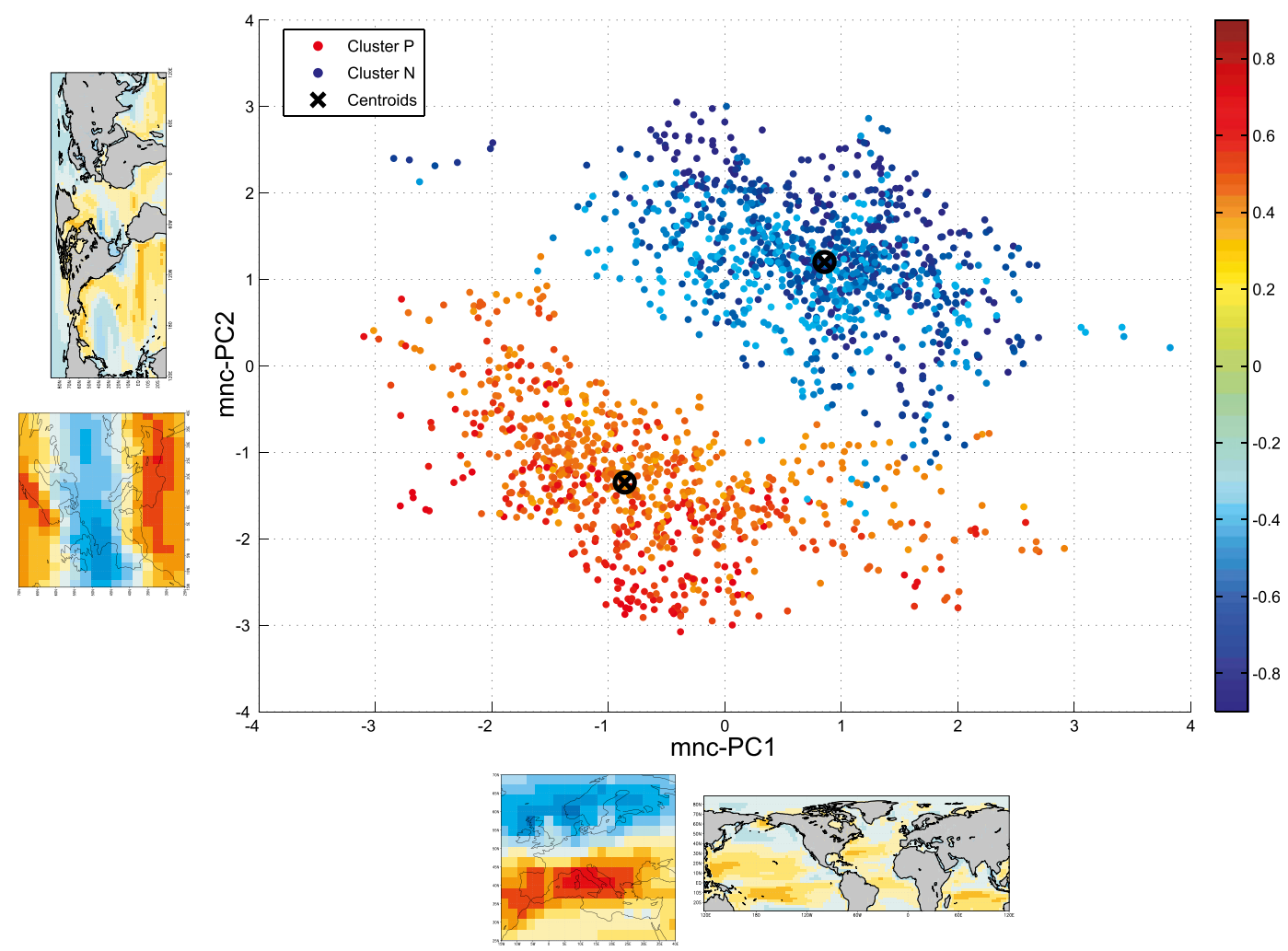

FIG. 4. Scatterplot of the 20-yr moving window's significant correlations (according to a 400-trial Monte Carlo test at the 95\% significance level) between interannual PC (Euro-Mediterranean rainfall) and the Niño-3.4 index (positive correlations in red and negative correlations in blue), in relation to mnc-PC1 and mnc-PC2 values. Centroids are denoted with a black mark. For reference, rainfall and SST spatial patterns associated with mnc-PC1 and mnc-PC2 (from Fig. 3) are included in the axis.

These patterns, which reflect changing links between European rainfall and ENSO, could be forced by changes in the SST background state, as proposed in previous studies (López-Parages and Rodríguez-Fonseca 2012; López-Parages et al. 2015). Regarding this issue, the correlation map between the SSTs (obtained as 20-yr moving averages) and the leading mnc-PC is related to a warming of the western Pacific at tropical latitudes, the equatorial and northern subtropical Atlantic, and the southern Indian Ocean (Fig. 3c). The SST correlation map using the second mode (Fig. 3d) resembles the observed and simulated positive phase of the interdecadal Pacific oscillation (IPO), except for the negative correlations off the Central American coast (Mantua et al. 1997; Villamayor and Mohino 2015). Over the North Atlantic, a horseshoe pattern is also discerned, with positive correlations from the Labrador Sea to the east side of the tropical North Atlantic, and negative correlations over the Caribbean Sea and the Gulf Stream region. This pattern resembles changes in the regions of the subtropical gyres that are known to take place at multidecadal time scales (Latif and Barnett 1996; Tourre et al.
2001; Reverdin 2010). At this point it seems to be clear that these SST patterns play a noticeable role as modulator of the ENSO-Euro-Mediterranean rainfall teleconnection identified in section $3 \mathrm{a}$. Nevertheless, in a particular period these two mnc-EOFs can coexist, by construction, in different manners. Thus, it is important to determine the preferential values of mnc-PC1 and mncPC2 for which significant correlations between the leading observed rainfall EOF and $\mathrm{El}$ Niño $(\mathrm{P}$ and $\mathrm{N})$ are favored. A first comparison of the corresponding time series suggests that positive interannual correlations $(P$ periods) are related to negative values of mnc-PC1 and mnc-PC2, and vice versa (Fig. 3e). To further investigate this issue, the statistically significant correlations $\mathrm{P}$ and $\mathrm{N}$ are represented in a new base established by mnc-PC1 and mnc-PC2. Under this new base, the significant $\mathrm{P}$ and $\mathrm{N}$ correlations arrange in two different clusters (Fig. 4). Note that these two clusters behave in an approximately linear way under the new base, with most $\mathrm{P}(\mathrm{N})$ windows under negative (positive) values of mnc-PC1 and mnc$\mathrm{PC} 2$, consistent with the hypothesis deduced from Fig. 3e. In the following analysis we have characterized each 
a)

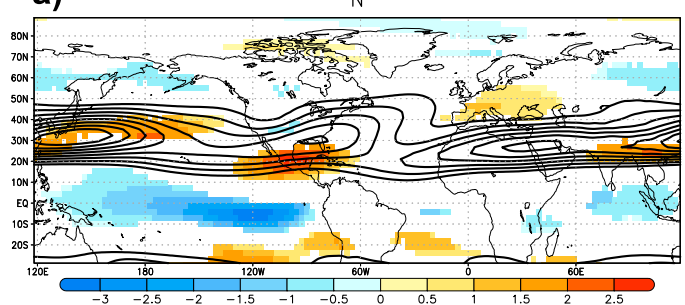

C)

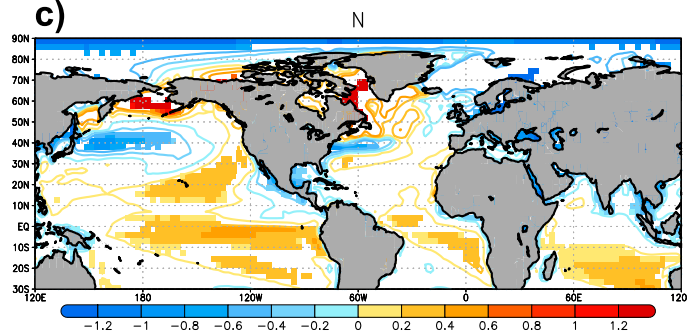

b)

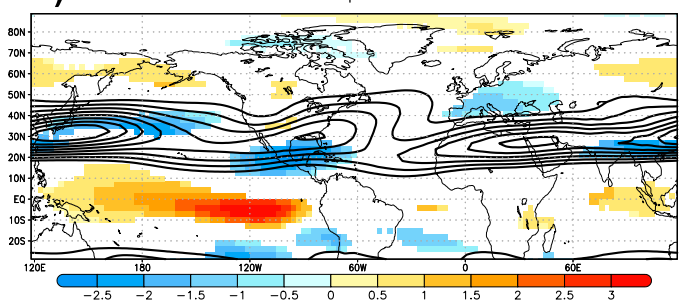

d)

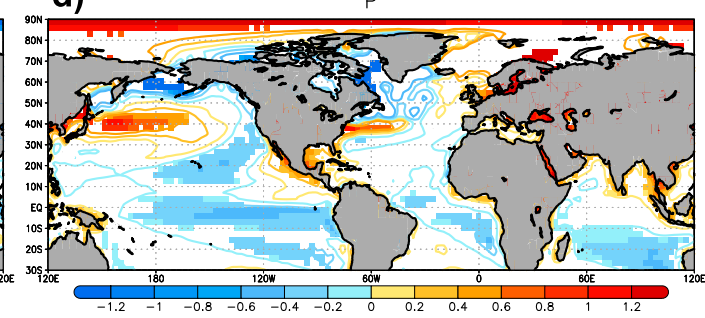

FIG. 5. Multidecadal patterns: (a),(b) U200 ( $\mathrm{m} \mathrm{s}^{-1}$ ) and (c),(d) SST (K) weighted-regression maps [see Eqs. (3) and (4)] onto mnc-PC1 and mnc-PC2, for (left) N and (right) P periods. Only the $90 \%$ significant areas according to a random-phase test [see Ebisuzaki (1997) for details] with 400 resamplings are shaded. For U200 in (a),(b), climatological values are plotted in contours; the minimum value represented is $20 \mathrm{~m} \mathrm{~s}^{-1}$ (CI $\left.=5 \mathrm{~m} \mathrm{~s}^{-1}\right)$. For SST in (c), (d), nonsignificant values are also contoured. The minimum (maximum) contour plotted, for positive (negative) values, is $0.1(-0.1) \mathrm{K}$, with $\mathrm{CI}=0.2 \mathrm{~K}$.

cluster by its corresponding centroid obtained from a $k$-means procedure [see section $2 \mathrm{~b}(3)]$.

\section{c. Modulating factors}

As previously noted in section 1, López-Parages et al. (2015) hypothesize that the changing teleconnection between ENSO and the Euro-Mediterranean rainfall is associated with multidecadal variations in the zonal mean flow at the upper troposphere $(200 \mathrm{hPa})$ in phase with internal multidecadal changes in the underlying SSTs. This hypothesis relies on the fact that zonal winds in upper-tropospheric levels are directly related to the meridional temperature gradient (i.e., they are in thermal wind balance). Thus, noticeable changes in meridional SST gradients at midlatitudes could alter the vertical (geostrophic) shear of the horizontal wind (thermal wind) in a way that results in modified jet streams and, hence, in different tropical-extratropical teleconnection pathways. In this work we test if this hypothesis could explain the distinct ENSO signature on Euro-Mediterranean rainfall, in $\mathrm{P}$ and $\mathrm{N}$ periods, of piControl-CMIP5 simulations. To represent the feature in each type of period for all CMIP5 models in an average sense, we have calculated the centroid of each cluster in Fig. 4 using a $k$-means procedure. The spatial patterns of the multidecadal anomalous SST and the multidecadal zonal wind at $200 \mathrm{hPa}$ (U200) for the aforementioned clusters-associated with $\mathrm{P}$ and $\mathrm{N}$ periods - are calculated by multiplying the coordinates of the centroid $k\left(\alpha_{k}, \gamma_{k}\right)$ in the mnc-PC1 and mnc-PC2 base, by the corresponding projection of each mnc-PC onto the pertinent low-frequency filtered (obtained as 20-yr moving averages) variable (see Fig. 5):

$$
R_{k, \mathrm{U} 200}=\left(\frac{\alpha_{k} \mathrm{mnc}-\mathrm{PC} 1 \cdot \mathrm{U} 200+\gamma_{k} \mathrm{mnc}-\mathrm{PC} 2 \cdot \mathrm{U} 200}{W}\right)
$$

and

$$
R_{k, \mathrm{SST}}=\left(\frac{\alpha_{k} \mathrm{mnc}-\mathrm{PC} 1 \cdot \mathrm{SST}+\gamma_{k} \mathrm{mnc}-\mathrm{PC} 2 \cdot \mathrm{SST}}{W}\right),
$$

where $W$ indicates the number of 20 -yr sliding windows considered. Figure 5 shows, therefore, the weighted projections of mnc-PC1 and mnc-PC2 onto SST and U200 according to the coordinates of the corresponding centroid that characterize each cluster. In this way, the common variability among the different models is maximized.

Note that in Fig. 5 we are showing the anomalous climatological state on which an El Niño or a La Niña influences the Euro-Mediterranean rainfall in the socalled P (Figs. 2b,d) and N (Figs. 2a,c) periods. The first characteristic to highlight from Fig. 5 is the similar, but opposite, patterns found in $\mathrm{P}$ and $\mathrm{N}$, which is explained by the linear disposition of the clusters in the new base (see mnc-PC1 vs mnc-PC2 in Fig. 4; note also the similar $\alpha$ and $\gamma$ coefficients obtained for both centroids in Table 3 ). Regarding the SST, an anomalous spatial pattern 
TABLE 3. Coordinates of each centroid shown in Fig. 4.

\begin{tabular}{lcc}
\hline & Centroid P & Centroid N \\
\hline$\alpha$ & -0.9 & 0.9 \\
$\gamma$ & -1.4 & 1.2 \\
\hline
\end{tabular}

resembling a negative (positive) IPO appears highlighted in $\mathrm{P}(\mathrm{N})$ over the Pacific basin, identifying its characteristic horseshoe signal at midlatitudes. This spatial pattern resembles a negative (positive) mncEOF2 over the North Pacific (see Figs. 3d and 5c,d), but with an enhanced meridional SST gradient around $30^{\circ} \mathrm{N}$, which is also influenced by the strong cooling (warming) of the tropical Pacific associated with a negative (positive) mnc-EOF1 (see Figs. 3c and 5c,d). Over the Caribbean Sea and over the coast of California positive (negative) SST anomalies are found in $\mathrm{P}(\mathrm{N})$. In the former case this feature reflects the mnc-EOF2 signature, whereas in the latter case it reflects the influence of both mnc-EOF1 and mnc-EOF2. Regarding the upper-level tropospheric mean flow, a weakened (strengthened) jet is found in $\mathrm{P}(\mathrm{N})$ over the North $\mathrm{Pa}$ cific and the Central American continent (Figs. 5a,b). Considering that jet streams are partially caused by the meridional temperature gradient, a significant change in the jets is expected if the air temperature gradients are altered through the thermal wind balance. Following this reasoning, the aforementioned weakening (enhancement) of the jet streams in $\mathrm{P}(\mathrm{N})$ is coherent with the anomalous underlying SST pattern, which appears in a way that diminishes (amplifies) the climatological SST meridional gradient over these areas (see Fig. S1 in the supplementary material for details).

Up to now, this subsection has been focused on the analysis of the anomalous climatological state obtained for $\mathrm{P}$ and $\mathrm{N}$ (Fig. 5). But interannual phenomena such as El Niño take place superimposed on such climatologies and, as was shown in section $3 \mathrm{a}$, in those cases the extratropical impacts are noticeably different over the NAE sector (Fig. 2). A remaining and unanswered question is to what extent the low-frequency variability of the jet streams (Figs. 5a,b) is the responsible for the distinct wave activity identified, in $\mathrm{P}$ and $\mathrm{N}$, in relation to an almost the same $\mathrm{El}$ Niño forcing. To provide an answer to it we have calculated the Rossby wavenumber $K_{s}$, whose relative maximum values can be used as a sign of stationary Rossby waveguides (Hoskins and Ambrizzi 1993). According to Hoskins and Ambrizzi (1993) $K_{s}$ can be expressed as

$$
K_{s}=\left(\frac{\beta-\frac{\partial^{2} U}{\partial y^{2}}}{U}\right)^{1 / 2}
$$

where $\beta$ represents the change of planetary vorticity with latitude ( $\partial f / \partial y)$ and $U$ the zonal mean flow.

In Fig. 6 the rotational responses represented in Figs. 2e,f in relation to CMIP5 models are shown again (shaded in Figs. 2e,f but contoured in Fig. 6) together with the corresponding climatological $K_{s}$ values (shaded in Fig. 6; see top and middle panels). Although the TNH pattern is reproduced in both the $\mathrm{P}$ and $\mathrm{N}$ samples, a remarkable enhancement of the downstream impact over the North Atlantic appears for the former case (Fig. 6, top). This feature is explained by the reinforced waveguides over the North Pacific and the North American continent in $\mathrm{P}$ (shaded red in Fig. 6, bottom), which favor the Rossby wave propagation associated with ENSO from the tropical Pacific toward the NAE sector (contoured in Fig. 6, bottom).

According to the definition of $K_{s}$ [Eq. (5)], in those areas surrounding the extratropical westerly jets $(U>0)$, $K_{s}$ is defined only if the numerator of Eq. (5) is positive. Moreover, its magnitude, which is modulated by the intensity of $U$, depends on the second-order derivative of the zonal flow, that is, on its concavity. According to this, jet streams enhance their efficiency to propagate stationary Rossby waves in those areas where they are changed in a way such that $\partial^{2} U / \partial y^{2}<0$.

By carefully looking at the $\mathrm{P}-\mathrm{N}$ differences in the first- and second-order derivatives of the climatological U200 over the North Pacific and the North American continent (shaded and contoured, respectively, in Fig. S2), one can relate the enhanced Rossby waveguides in $\mathrm{P}$ with respect to $\mathrm{N}$ (Fig. 6, bottom) to the weakened climatological U200 found, approximately, $10^{\circ}-20^{\circ}$ farther south (Figs. 5a,b). In turn, this weakened (strengthened) climatological U200 in P (N) over the North Pacific and the North American continent were previously related to the anomalous climatological SST meridional gradient. Thus, according to our results, the nonstationary teleconnection between ENSO and the Euro-Mediterranean rainfall identified in CMIP5 models (Fig. 2) can be explained by the change in the Rossby waves propagation from the tropical Pacific to the NAE sector (Fig. 6), which in turn is produced by the low-frequency variability of the jet streams associated with the underlying SST (Fig. 5; see also Figs. S1 and S2).

\section{Summary and final discussion}

The internal contribution of the ocean-atmosphere coupled system to the nonstationary teleconnection between El Niño and the leading Euro-Mediterranean anomalous rainfall mode in late winter-early spring (López-Parages and Rodríguez-Fonseca 2012; LópezParages et al. 2015) has been thoroughly examined in 

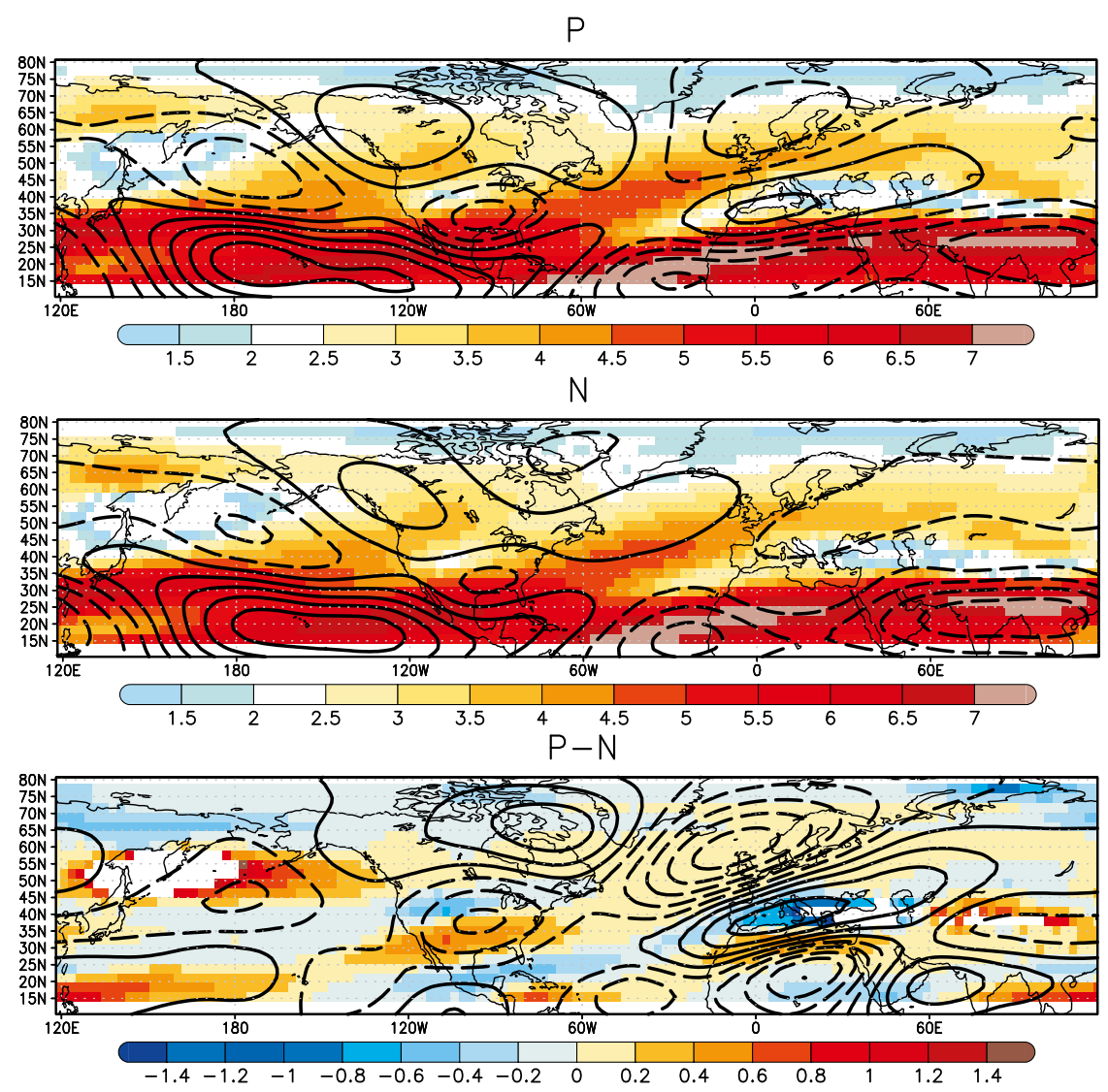

FIG. 6. Changing interannual teleconnection. Mean stationary Rossby wavenumber $K_{s}$ at $200 \mathrm{hPa}$ (shaded) together with the streamfunction at $200 \mathrm{hPa}$ (contoured) averaged over the 18 CMIP5 models in those periods in which the correlation between the interannual PC of EuroMediterranean rainfall and the Niño-3.4 index is (top) positive or (middle) negative at the $95 \%$ significance level (according to a 400-trial Monte Carlo test). (bottom) The difference $\mathrm{P}-\mathrm{N}$. In (top) and (middle), $\mathrm{CI}=4 \times 10^{5} \mathrm{~m} \mathrm{~s}^{-2}$, with a minimum contour of 2 and $-2 \times 10^{5} \mathrm{~m} \mathrm{~s}^{-2}$ for positive and negative streamfunction values, respectively. For (bottom), CI $=2 \times 10^{5} \mathrm{~m} \mathrm{~s}^{-2}$, with $10^{5}$ and $-10^{5} \mathrm{~m} \mathrm{~s}^{-2}$ being the minimum contour plotted for positive and negative values, respectively.

this study. For this purpose, long-term preindustrial control (piControl) simulations from 18 different models involved in phase 5 of the Coupled Model Intercomparison Project (CMIP5) have been used.

For each model, the Euro-Mediterranean rainfall variability mode that is the spatially closest to the leading observational one (from the so-called CMIP5 independent EOFs) has been selected. Then, those 20-yr periods, for which a significant correlation between the corresponding PC and the Niño-3.4 index is found, are grouped and analyzed as a whole by computing ensemble means of regression maps for different variables. The resulting patterns reflect a changing impact of ENSO on the Euro-Mediterranean rainfall in a way consistent with the spatial structures related to the nonstationary observational link (Mariotti et al. 2002; Knippertz et al. 2003; Sutton and Hodson 2003;
Gouirand and Moron 2003; Greatbatch et al. 2004). This feature is characterized in both observations and CMIP5 models by a noticeably distinct downstream impact of ENSO-related Rossby waves over the NAE sector among different periods.

To address the low-frequency variability associated with the background state that could be modulating the ENSO teleconnection with the Euro-Mediterranean rainfall, the aforementioned changing link has been explored by an alternative approach. This new methodology looks for the time evolution of the teleconnection by calculating the principal directions in which the 20-yr correlation maps between ENSO and the Euro-Mediterranean rainfall evolve (see the so-called El Niño-rainfall EOF in section 2). This new procedure, which highlights the common variability among the different CMIP5 models, makes possible the characterization 
of the ENSO teleconnection with the Euro-Mediterranean rainfall under a new base. Those periods with significant correlations between the PC from the independent EOFs of rainfall and the Niño-3.4 index are divided, in accordance to the sign of the correlation (positive or negative), into two different clusters in the new mathematical base. Subsequently, as SST and zonal mean flow at the upper troposphere $(200 \mathrm{hPa})$ over the North Pacific Ocean (approximately between $30^{\circ}$ and $60^{\circ} \mathrm{N}$ ) have been both addressed as modulators of the ENSOEuro-Mediterranean rainfall teleconnection at interannual time scales (López-Parages et al. 2015), the spatial patterns of these fields, which are associated with the basic mean state of the cluster centroids, have been obtained.

According to our results, those periods for which a strong (weak) ENSO-related wave activity is identified over the NAE are characterized by a weakened (strengthened) jet stream over the North Pacific and the Central American continent, which favors (undermines) the propagation of Rossby waves from the tropical $\mathrm{Pa}$ cific to extratropical latitudes and their downstream impact over the Euro-Mediterranean region. Our results suggest that these changes in the upper-tropospheric mean flow are associated with multidecadal variability of the underlying SST, which alters the meridional temperature gradient of Earth's atmosphere and hence the normal configuration of the jet streams.

These conclusions are inferred from the cluster centroids analysis, in an attempt to illustrate the background conditions associated with each cluster in ensemble maps for all CMIP5 models. The validity of the resulting spatial patterns (and, hence, the resulting modulators of the teleconnection) for each model should, however, be interpreted with caution. Thus, the patterns shown in Fig. 5 will be realistic for a specific model if their corresponding clusters are organized in a similar way as the ensemble centroids plotted in Fig. 4 (as occurs for most of the models; see also Fig. S3 in the supplementary material). Otherwise the link between SST and upper-tropospheric winds could still be valid, but not precisely in the way illustrated in Fig. 5. The analysis of the particular characteristics of each model is outside of the scope of the present paper but our results encourage further studies analyzing the intermodel differences between the modulating factors of the ENSO teleconnection with Euro-Mediterranean rainfall in CMIP5 simulations. According to the tropospheric and the stratospheric pathways connecting ENSO with the NAE climate (see description in the introduction), it would be of particular interest to compare the modulators between the "high top" and "low top" CMIP5 models, which are classified depending on the model layers in the stratosphere. In addition, in view of the documented effect of SST variability on blocking (which, in turn, is associated with upper-tropospheric Rossby wave breaking; see, e.g., Gollan et al. 2015), it would also be interesting to see in the future if the changes at multidecadal time scales in the upper-tropospheric flow identified here in association with the underlying SST and the nonstationary ENSO-NAE teleconnection would be closely related to multidecadal blocking variations.

The present study lends support to the notion that the nonstationary behavior of the ENSO-Euro-Mediterranean rainfall teleconnection found in the observations can be reproduced by internal variability of the coupled oceanatmosphere system; in particular, it indicates a changing ENSO-related Rossby wave propagation from the tropical Pacific to the NAE sector modulated by the sea surface temperature.

Acknowledgments. The authors thank the three anonymous reviewers for their helpful comments, which greatly helped to improve the manuscript. We acknowledge the World Climate Research Programme's Working Group on Coupled Modelling, which is responsible for CMIP, and we thank the climate modeling groups for producing and making available their model output. For CMIP and U.S. Department of Energy's Program for Climate Model Diagnosis and Intercomparison provides coordinating support and led development of software infrastructure in partnership with the Global Organization for Earth System Science Portals. We also thank Julian Villamayor Moreno for his help in downloading all the CMIP data needed for this study. This study was supported by the European project PREFACE (603521), and the Spanish projects PRESTAMOS (CGL2012-34997), TRACS (CGL2009-10285) and MULCLIVAR (CGL2012- 38923C02-01). In particular, JLP thanks the FPI grant (BES2010-042234) associated with the TRACS project.

\section{REFERENCES}

Ambrizzi, T., B. J. Hoskins, and H.-H. Hsu, 1995: Rossby wave propagation and teleconnection patterns in the austral winter. J. Atmos. Sci., 52, 3661-3672, doi:10.1175/1520-0469(1995)052<3661: RWPATP $>2.0 . \mathrm{CO} ; 2$.

An, S.-I., Z. Ye, and W. W. Hsieh, 2006: Changes in the leading ENSO modes associated with the late 1970s climate shift: Role of surface zonal current. Geophys. Res. Lett., 33, L14609, doi:10.1029/2006GL026604.

Bao, Q., and Coauthors, 2013: The Flexible Global OceanAtmosphere-Land System model, spectral version 2: FGOALS-s2. Adv. Atmos. Sci., 30, 561-576, doi:10.1007/ s00376-012-2113-9.

Barnston, A., and R. Livezey, 1987: Classification, seasonality and persistence of low-frequency atmospheric circulation patterns. Mon. Wea. Rev., 115, 1083-1126, doi:10.1175/1520-0493(1987)115<1083: CSAPOL $>2.0 . \mathrm{CO} ; 2$.

Bell, C. J., L. J. Gray, A. J. Charlton-Perez, M. M. Joshi, and A. A. Scaife, 2009: Stratospheric communication of El Niño 
teleconnections to European winter. J. Climate, 22, 40834096, doi:10.1175/2009JCLI2717.1.

Bentsen, M., and Coauthors, 2013: The Norwegian Earth System Model, NorESM1-M. Part 1: Description and basic evaluation of the physical climate. Geosci. Model Dev., 6, 687-720, doi:10.5194/gmd-6-687-2013.

Bladé, I., M. Newman, M. A. Alexander, and J. D. Scott, 2008: The late fall extratropical response to ENSO: Sensitivity to coupling and convection in the tropical west Pacific. J. Climate, 21, 6101-6118, doi:10.1175/2008JCLI1612.1.

Branstator, G., 1983: Horizontal energy propagation in a barotropic atmosphere with meridional and zonal structure. J. Atmos. Sci., 40, 1689-1708, doi:10.1175/1520-0469(1983)040<1689: HEPIAB $>2.0 . \mathrm{CO} ; 2$.

- 2002: Circumglobal teleconnections, the jet stream waveguide, and the North Atlantic Oscillation. J. Climate, 15, 1893-1910, doi:10.1175/1520-0442(2002)015<1893:CTTJSW>2.0.CO;2.

Brönnimann, S., 2007: Impact of El Niño-Southern Oscillation on European climate. Rev. Geophys., 45, RG3003, doi:10.1029/ 2006RG000199.

Butler, A. H., L. M. Polvani, and C. Deser, 2014: Separating the stratospheric and tropospheric pathways of El Niño-Southern Oscillation teleconnections. Environ. Res. Lett., 9, 024014, doi:10.1088/1748-9326/9/2/024014.

Cagnazzo, C., and E. Manzini, 2009: Impact of the stratosphere on the winter tropospheric teleconnections between ENSO and the North Atlantic and European region. J. Climate, 22, 12231238, doi:10.1175/2008JCLI2549.1.

Chylek, P., J. Li, M. Dubey, M. Wang, and G. Lesins, 2011: Observed and model simulated 20th century Arctic temperature variability: Canadian Earth System Model CanESM2. Atmos. Chem. Phys. Discuss., 11, 22 893-22 907, doi:10.5194/acpd-11-22893-2011.

Domeisen, D. I. V., A. H. Butler, K. Fröhlich, M. Bittner, W. A. Müller, and J. Baehr, 2015: Seasonal predictability over Europe arising from El Niño and stratospheric variability in the MPI-ESM Seasonal Prediction System. J. Climate, 28, 256271, doi:10.1175/JCLI-D-14-00207.1.

Dufresne, J.-L., and Coauthors, 2013: Climate change projections using the IPSL-CM5 Earth system model: From CMIP3 to CMIP5. Climate Dyn., 40, 2123-2165, doi:10.1007/s00382-012-1636-1.

Ebisuzaki, W., 1997: A method to estimate the statistical significance of a correlation when the data are serially correlated. $\mathrm{J}$. Climate, 10, 2147-2153, doi:10.1175/1520-0442(1997)010<2147: AMTETS $>2.0 . \mathrm{CO} ; 2$.

Fraedrich, K., and K. Müller, 1992: Climate anomalies in Europe associated with ENSO extremes. Int. J. Climatol., 12, 25-31, doi:10.1002/joc.3370120104.

García-Serrano, J., B. Rodríguez-Fonseca, I. Bladé, P. Zurita-Gotor, and A. de La Cámara, 2011: Rotational atmospheric circulation during North Atlantic-European winter: The influence of ENSO. Climate Dyn., 37, 1727-1743, doi:10.1007/s00382-010-0968-y.

Garfinkel, C. I., and D. L. Hartmann, 2008: Different ENSO teleconnections and their effects on the stratospheric polar vortex. J. Geophys. Res., 113, D18114, doi:10.1029/2008JD009920.

Gent, P. R., and Coauthors, 2011: The Community Climate System Model version 4. J. Climate, 24, 4973-4991, doi:10.1175/ 2011JCLI4083.1.

Giorgetta, M. A., and Coauthors, 2013: Climate and carbon cycle changes from 1850 to 2100 in MPI-ESM simulations for the Coupled Model Intercomparison Project phase 5. J. $A d v$. Model. Earth Syst., 5, 572-597, doi:10.1002/jame.20038.

Gollan, G., R. J. Greatbatch, and T. Jung, 2015: Origin of variability in Northern Hemisphere winter blocking on interannual to decadal timescales. Geophys. Res. Lett., 42, 10 037-10 046, doi:10.1002/2015GL066572.

Gouirand, I., and V. Moron, 2003: Variability of the impact of El Niño-Southern Oscillation on sea-level pressure anomalies over the North Atlantic in January to March (1874-1996). Int. J. Climatol., 23, 1549-1566, doi:10.1002/joc.963.

$\longrightarrow,-$, and E. Zorita, 2007: Teleconnections between ENSO and North Atlantic in an ECHO-G simulation of the 1000-1990 period. Geophys. Res. Lett., 34, L06705, doi:10.1029/2006GL028852.

Greatbatch, R. J., J. Lu, and K. A. Peterson, 2004: Nonstationary impact of ENSO on Euro-Atlantic winter climate. Geophys. Res. Lett., 31, L02208, doi:10.1029/2003GL018542.

Honda, M., H. Nakamura, J. Ukita, I. Kousaka, and K. Takeuchi, 2001: Interannual seesaw between the Aleutian and Icelandic lows. Part I: Seasonal dependence and life cycle. J. Climate, 14, 1029-1042, doi:10.1175/1520-0442(2001)014<1029:ISBTAA>2.0.CO;2.

Hoskins, B. J., and D. J. Karoly, 1981: The steady linear response of a spherical atmosphere to thermal and orographic forcing. J. Atmos. Sci., 38, 1179-1196, doi:10.1175/1520-0469(1981)038<1179: TSLROA $>2.0 . \mathrm{CO} ; 2$.

— , and T. Ambrizzi, 1993: Rossby wave propagation on a realistic longitudinally varying flow. J. Atmos. Sci., 50, 1661-1671, doi:10.1175/1520-0469(1993)050<1661:RWPOAR > 2.0.CO;2.

Ineson, S., and A. A. Scaife, 2009: The role of the stratosphere in the European climate response to El Niño. Nat. Geosci., 2, 32 36, doi:10.1038/ngeo381.

Kang, I.-S., I. U. Rashid, F. Kucharski, M. Almazroui, and A. K. Alkhalaf, 2015: Multidecadal changes in the relationship between ENSO and wet-season precipitation in the Arabian Peninsula. J. Climate, 28, 4743-4752, doi:10.1175/JCLI-D-14-00388.1.

Knippertz, P., U. Ulbrich, F. Marques, and J. Corte-Real, 2003: Decadal changes in the link between El Niño and springtime North Atlantic Oscillation and European-North African rainfall. Int. J. Climatol., 23, 1293-1311, doi:10.1002/joc.944.

Latif, M., and T. P. Barnett, 1996: Decadal climate variability over the North Pacific and North America: Dynamics and predictability. J. Climate, 9, 2407-2423, doi:10.1175/1520-0442(1996)009<2407: DCVOTN $>2.0 . \mathrm{CO} ; 2$.

Lee, S.-K., D. B. Enfield, and C. Wang, 2008: Why do some El Niños have no impact on tropical North Atlantic SST? Geophys. Res. Lett., 35, L16705, doi:10.1029/2008GL034734.

Livezey, R. E., and K. C. Mo, 1987: Tropical-extratropical teleconnections during the Northern Hemisphere winter. Part II: Relationships between monthly mean Northern Hemisphere circulation patterns and proxies for tropical convection. Mon. Wea. Rev., 115, 3115-3132, doi:10.1175/1520-0493(1987)115<3115: TETDTN $>2.0 . \mathrm{CO} ; 2$.

Lloyd, S. P., 1982: Least squares quantization in PCM. IEEE Trans. Info. Theory, 28, 129-137.

López-Parages, J., and B. Rodríguez-Fonseca, 2012: Multidecadal modulation of El Niño influence on the Euro-Mediterranean rainfall. Geophys. Res. Lett., 39, L02704, doi:10.1029/ 2011 GL050049.

,-- , and L. Terray, 2015: A mechanism for the multidecadal modulation of ENSO teleconnection with Europe. Climate Dyn., 45, 867-880, doi:10.1007/s00382-014-2319-x.

,,-- D. Dommenget, and C. Frauen, 2016: ENSO influence on the North Atlantic European climate: A non-linear and non-stationary approach. Climate Dyn., 47, 2071-2084, doi:10.1007/s00382-015-2951-0.

Mantua, N. J., S. R. Hare, Y. Zhang, J. M. Wallace, and R. C. Francis, 1997: A Pacific interdecadal climate oscillation with impacts on salmon production. Bull. Amer. Meteor. 
Soc., 78, 1069-1079, doi:10.1175/1520-0477(1997)078<1069: APICOW $>2.0 . \mathrm{CO} ; 2$.

Manzini, E., M. A. Giorgetta, M. Esch, L. Kornblueh, and E. Roeckner, 2006: The Influence of sea surface temperatures on the northern winter stratosphere: Ensemble simulations with the MAECHAM5 model. J. Climate, 19, 3863-3881, doi:10.1175/JCLI3826.1.

Mariotti, A., N. Zeng, and K.-M. Lau, 2002: Euro-Mediterranean rainfall and ENSO_A seasonally varying relationship. Geophys. Res. Lett., 29, 1621, doi:10.1029/2001GL014248.

Martin, G., and Coauthors, 2011: The HadGEM2 family of Met Office Unified Model climate configurations. Geosci. Model Dev., 4, 723-757, doi:10.5194/gmdd-4-765-2011.

Mo, K. C., and R. E. Livezey, 1986: Tropical-extratropical geopotential height teleconnections during the Northern Hemisphere winter. Mon. Wea. Rev., 114, 2488-2515, doi:10.1175/ 1520-0493(1986)114<2488:TEGHTD > 2.0.CO;2.

Moron, V., and I. Gouirand, 2003: Seasonal modulation of the El Niño-Southern Oscillation relationship with sea level pressure anomalies over the North Atlantic in October-March 1873-1996. Int. J. Climatol., 23, 143-155, doi:10.1002/joc.868.

_ lation upon weather regimes over Europe and the North Atlantic during boreal winter. Int. J. Climatol., 23, 363-379, doi:10.1002/joc. 890 .

North, G. R., T. L. Bell, R. F. Cahalan, and F. J. Moeng, 1982: Sampling errors in the estimation of empirical orthogonal functions. Mon. Wea. Rev., 110, 699, doi:10.1175/1520-0493(1982)110<0699: SEITEO $>2.0 . \mathrm{CO} ; 2$.

Pozo-Vázquez, D., S. R. Gámiz-Fortis, J. Tovar-Pescador, M. J. Esteban-Parra, and Y. Castro-Díez, 2005: El Niño-Southern Oscillation events and associated European winter precipitation anomalies. Int. J. Climatol., 25, 17-31, doi:10.1002/joc.1097.

Quadrelli, R., and J. M. Wallace, 2002: Dependence of the structure of the Northern Hemisphere annular mode on the polarity of ENSO. Geophys. Res. Lett., 29, 2132, doi:10.1029/ 2002 GL015807.

Reverdin, G., 2010: North Atlantic subpolar gyre surface variability (1895-2009). J. Climate, 23, 4571-4584, doi:10.1175/ 2010JCLI3493.1.

Richter, J. H., C. Deser, and L. Sun, 2015: Effects of stratospheric variability on El Niño teleconnections. Environ. Res. Lett., 10, 124021, doi:10.1088/1748-9326/10/12/124021.

Rodríguez-Fonseca, B., and Coauthors, 2016: A review of ENSO influence on the North Atlantic: A non-stationary signal. Atmosphere, 7, 87, doi:10.3390/atmos7070087.

Rotstayn, L. D., M. A. Collier, M. R. Dix, Y. Feng, H. B. Gordon, S. P. O'Farrell, I. N. Smith, and J. Syktus, 2010: Improved simulation of Australian climate and ENSO-related rainfall variability in a global climate model with an interactive aerosol treatment. Int. J. Climatol., 30, 1067-1088, doi:10.1002/joc.1952.

Sakamoto, T., and Coauthors, 2012: MIROC4h-A new highresolution atmosphere-ocean coupled general circulation model. J. Meteor. Soc. Japan, 90, 325-359, doi:10.2151/jmsj.2012-301.

Schmidt, G. A., and Coauthors, 2014: Configuration and assessment of the GISS ModelE2 contributions to the CMIP5 archive. J. Adv. Model. Earth Syst., 6, 141-184, doi:10.1002/2013MS000265.

Shaman, J., 2014: The seasonal effects of ENSO on European precipitation: Observational analysis. J. Climate, 27, 64236438, doi:10.1175/JCLI-D-14-00008.1.

_- , and E. Tziperman, 2011: An atmospheric teleconnection linking ENSO and southwestern European precipitation. J. Climate, 24, 124-139, doi:10.1175/2010JCLI3590.1.
Sutton, R. T., and D. L. R. Hodson, 2003: Influence of the ocean on North Atlantic climate variability 1871-1999. J. Climate, 16, 32963313, doi:10.1175/1520-0442(2003)016<3296:IOTOON >2.0.CO;2.

Swarztrauber, P., and R. Sweet, 1975: Efficient FORTRAN subprograms for the solution of elliptic partial differential equations. NCAR Tech. Note NCAR/TN-109+IA, 160 pp., doi:10.5065/D6542KJT.

Taylor, K. E., R. J. Stouffer, and G. A. Meehl, 2012: An overview of CMIP5 and the experiment design. Bull. Amer. Meteor. Soc., 93, 485-498, doi:10.1175/BAMS-D-11-00094.1.

Torrence, C., and P. J. Webster, 1998: The annual cycle of persistence in the El Niño/Southern Oscillation. Quart. J. Roy. Meteor. Soc., 124, 1985-2004, doi:10.1002/qj.49712455010.

Tourre, Y. M., B. Rajagopalan, Y. Kushnir, M. Barlow, and W. B. White, 2001: Patterns of coherent decadal and interdecadal climate signals in the Pacific basin during the $20^{\text {th }}$ century. Geophys. Res. Lett., 28, 2069-2072, doi:10.1029/2000GL012780.

Trenberth, K. E., G. W. Branstator, D. Karoly, A. Kumar, N.-C. Lau, and C. Ropelewski, 1998: Progress during TOGA in understanding and modeling global teleconnections associated with tropical sea surface temperatures. J. Geophys. Res., 103, 14 291-14 324, doi:10.1029/97JC01444.

van Oldenborgh, G. J., 2005: Comments on "Predictability of winter climate over the North Atlantic European region during ENSO events." J. Climate, 18, 2770-2772, doi:10.1175/JCLI3441.1. , and G. Burgers, 2005: Searching for decadal variations in ENSO precipitation teleconnections. Geophys. Res. Lett., 32, L15701, doi:10.1029/2005GL023110.

Villamayor, J., and E. Mohino, 2015: Robust Sahel drought due to the interdecadal Pacific oscillation in CMIP5 simulations. Geophys. Res. Lett., 42, 1214-1222, doi:10.1002/2014GL062473.

Voldoire, A., and Coauthors, 2013: The CNRM-CM5.1 global climate model: Description and basic evaluation. Climate Dyn., 40, 2091-2121, doi:10.1007/s00382-011-1259-y.

Volodin, E., N. Dianskii, and A. Gusev, 2010: Simulating presentday climate with the INMCM4.0 coupled model of the atmospheric and oceanic general circulations. Izv. Atmos. Ocean. Phys., 46, 414-431, doi:10.1134/S000143381004002X.

Ward, M. N., and A. Navarra, 1997: Pattern analysis of SST-forced variability in ensemble GCM simulations: Examples over Europe and the tropical Pacific. J. Climate, 10, 2210-2220, doi:10.1175/1520-0442(1997)010<2210:PAOSFV>2.0.CO;2.

Watanabe, M., and Coauthors, 2010: Improved climate simulation by MIROC5: Mean states, variability, and climate sensitivity. J. Climate, 23, 6312-6335, doi:10.1175/2010JCLI3679.1.

Watanabe, S., and Coauthors, 2011: MIROC-ESM: Model description and basic results of CMIP5-20c3m experiments. Geosci. Model Dev., 4, 845-872, doi:10.5194/gmdd-4-1063-2011.

$\mathrm{Wu}, \mathrm{A}$., and W. W. Hsieh, 2004a: The nonlinear association between ENSO and the Euro-Atlantic winter sea level pressure. Climate Dyn., 23, 859-868, doi:10.1007/s00382-004-0470-5.

—, and - 2004b: The nonlinear Northern Hemisphere winter atmospheric response to ENSO. Geophys. Res. Lett., 31, L02203, doi:10.1029/2003GL018885.

Xin, X.-G., T.-W. Wu, and J. Zhang, 2013: Introduction of CMIP5 experiments carried out with the climate system models of Beijing Climate Center. Adv. Climate Change Res., 4, 41-49, doi:10.3724/SP.J.1248.2013.041.

Yukimoto, S., 2011: Meteorological Research Institute Earth System Model version 1 (MRI-ESM1): Model description. MRI Tech. Rep. 64, 88 pp. 